\title{
Short communication: Repeatability of differential goat bulk milk culture and associations with somatic cell count, total bacterial count, and standard plate count
}

\author{
G. Koop, ${ }^{* 1}$ N. Dik, $†$ M. Nielen, ${ }^{*}$ and L. J. A. Lipman $†$ \\ *Department of Farm Animal Health, Faculty of Veterinary Medicine, Utrecht University, Utrecht, the Netherlands \\ †Division Veterinary Public Health, Institute for Risk Assessment Sciences, Utrecht University, Utrecht, the Netherlands
}

\begin{abstract}
The aims of this study were to assess how different bacterial groups in bulk milk are related to bulk milk somatic cell count (SCC), bulk milk total bacterial count (TBC), and bulk milk standard plate count (SPC) and to measure the repeatability of bulk milk culturing. On 53 Dutch dairy goat farms, 3 bulk milk samples were collected at intervals of $2 \mathrm{wk}$. The samples were cultured for SPC, coliform count, and staphylococcal count and for the presence of Staphylococcus aureus. Furthermore, SCC (Fossomatic 5000, Foss, Hillerød, Denmark) and TBC (BactoScan FC 150, Foss) were measured. Staphylococcal count was correlated to SCC $(\mathrm{r}=0.40)$, TBC $(\mathrm{r}=0.51)$, and SPC $(\mathrm{r}=0.53)$. Coliform count was correlated to TBC $(\mathrm{r}=0.33)$, but not to any of the other variables. Staphylococcus aureus did not correlate to SCC. The contribution of the staphylococcal count to the SPC was $31 \%$, whereas the coliform count comprised only $1 \%$ of the SPC. The agreement of the repeated measurements was low. This study indicates that staphylococci in goat bulk milk are related to SCC and make a significant contribution to SPC. Because of the high variation in bacterial counts, repeated sampling is necessary to draw valid conclusions from bulk milk culturing.
\end{abstract}

Key words: bulk milk, somatic cell count, bacterial culture, dairy goat

Culturing bulk milk for specific bacterial groups can be used to identify causes of a high bulk milk total bacterial count (TBC) or high bulk milk SCC. Several studies in cattle showed that a higher frequency of isolation of Staphylococcus aureus (SA), Streptococcus agalactiae, or Streptococcus dysgalactiae was associated with an increased SCC, but coliform counts seemed not to affect SCC (Jayarao et al., 2004; Olde Riekerink et

Received September 8, 2009.

Accepted March 9, 2010.

${ }^{1}$ Corresponding author: g.koop@uu.nl al., 2006; Rysanek et al., 2009). This indicates that differential culturing of bulk milk can give some insight into the udder health status of a herd and may help farmers to find the cause of high TBC.

Studies on culturing of bulk milk in dairy goats are limited. The majority of these studies have a food quality perspective and look at a range of important food pathogens (Muehlherr et al., 2003; Kyozaire et al., 2005; Zeng et al., 2007; D'Amico et al., 2008) or report specifically on the presence of SA (Scherrer et al., 2004; Jørgensen et al., 2005). The presence of Mycoplasma spp. in bulk milk (de la Fe et al., 2009) and its relationship with SCC (Corrales et al., 2004; Contreras et al., 2008) has been studied. Associations of differential bacterial counts with SCC are reported in only 2 studies (Tirard-Collet et al., 1991; Foschino et al., 2002). These reports are based on small flocks (10-150 goats) and a limited number of farms (6 and 10); correlations between microbial groups and SCC are nonsignificant.

In a previous study (Koop et al., 2009), we found that goat bulk milk SCC is related to TBC. We hypothesized that IMI are probably the most important factor driving this correlation: IMI increases the SCC of the affected gland and also causes shedding of mastitis bacteria in the milk of this gland. Because IMI in goats are in the majority of cases caused by coagulasenegative staphylococci and SA (Bergonier et al., 2003; Contreras et al., 2007), we hypothesized that the count of staphylococci is related to SCC and to TBC.

In this study, bulk milk culturing was performed from an udder health perspective. Our aim was to assess whether coliform count (CC), staphylococcal count (SC), and the presence of SA are related to SCC, TBC, or SPC. Furthermore, we assessed the quantitative importance of coliforms and staphylococci in their contribution to the $\mathrm{TBC}$ or $\mathrm{SPC}$ and the repeatability of bulk milk bacterial culturing within a farm at 2-wk intervals.

Bulk milk samples were collected by trained milk truck drivers from 53 Dutch dairy goat farms that were randomly selected from one goat milk processing company. 
Samples were taken according to the National Mastitis Council (1999) bulk tank milk sample collection and handling guidelines. Each farm was sampled 3 times at 2-wk intervals in January, February, and March 2009. At approximately the same time (within $2 \mathrm{wk}$ ), routine sampling for TBC was performed. Three bulk milk samples were collected for each farm at each sampling moment. The milk samples were transported on melting ice. Two samples were sent to the Dutch laboratory for farm milk analysis and refrigerated below $3^{\circ} \mathrm{C}$ until SCC (Fossomatic 5000, Foss, Hillerød, Denmark) and TBC (BactoScan FC 150, Foss) measurement. The third sample was stored below $6^{\circ} \mathrm{C}$ and transported to the university laboratory for bacteriological culture.

The bacteriological procedures were according to Jayarao et al. (2004), with some modifications as stated below. The bulk milk samples were decimally diluted in peptone physiological salt solution and inocula of $100 \mu \mathrm{L}$ were used. Colonies on plate count agar (Oxoid Ltd., Basingstoke, UK) were counted after $72 \mathrm{~h}$ incubation at $30^{\circ} \mathrm{C}$. Coliform bacteria were cultured on MacConkey agar (Oxoid) and lactose-positive colonies were counted after $24 \mathrm{~h}$ of incubation at $37^{\circ} \mathrm{C}$. Staphylococcus spp. were cultured on mannitol salt agar (Oxoid). After $24 \mathrm{~h}$ of incubation, 3 colonies suggestive of SA were streaked on tryptic soy agar plates and incubated for $24 \mathrm{~h}$ at $37^{\circ} \mathrm{C}$. The isolates were examined for catalase and coagulase production. Colonies positive for catalase and coagulase were considered SA. Presence of SA in a sample was recorded as present (at least 1 out of 3 colonies positive) or absent (no colonies positive).

All bacterial and SCC data was normalized by $\log _{10}$ transformation. Normality of the log-transformed variables was investigated by visual inspection of the histograms and the Shapiro-Wilk statistic. Mean values per farm were calculated and minimum, maximum, and mean value and the standard deviation were used to describe these data. Spearman's rank correlation coefficients between the log-transformed SCC and bacterial counts were determined. The contribution of the different bacterial groups to the TBC and SPC was calculated as follows: for each farm, the geometric means for TBC, SPC, CC, and SC were calculated over the 3 samples. The geometric mean $\mathrm{CC}$ and $\mathrm{SC}$ were expressed as percentages of the mean TBC and SPC.

A linear mixed model was built, with SCC as dependent variable and with a random effect to correct for the repeated measures within farms. Random slopes or random intercepts or both were allowed if significant, based on the likelihood-ratio test. The factor "moment of sampling" (first, second, or third), the log-transformed variables $\mathrm{CC}$ and SC, and the binary variable "presence of SA" were used as independent variables in the model. First order autoregressive and compound symmetry covariance structures were tested and included if they improved the model significantly. The fit of the model and the assumptions of homoscedasticity, normality, and linearity were checked by visual inspection of the plots of standardized residuals against standardized predicted values, quantile-quantile plots and histograms of standardized residuals, and plots of standardized residuals against predictor variables.

The agreement between consecutive samplings of SCC, TBC, SPC, CC, and SC was determined by calculating the intraclass correlation coefficient (ICC), as described by Petrie and Watson (2006). The ICC expresses the proportion of the total variability in the observations that is attributable to the differences between the pairs as a percentage. The prevalence-adjusted, bias-adjusted kappa statistic was calculated to assess the agreement of SA isolation (coded as present or absent) between consecutive samplings.

The mixed model was built in $\mathrm{R}$ (version 2.7.1, $\mathrm{R}$ Foundation for Statistical Computing, Vienna, Austria). For the other analyses, we used SPSS for Windows (version 15.0.1, SPSS Inc., Chicago, IL).

The descriptive statistics for SCC and bacterial counts are given in Table 1. Staphylococcus aureus was detected in 85 of 159 samples (54\%). On $85 \%$ of the participating farms, SA was found in 1 or more milk samples. On $21 \%$ of the farms, SA was detected in all 3 bulk milk samples. Staphylococci were present in all milk samples and coliforms were present in $71 \%$ of the samples and were cultured at least once in $87 \%$ of the farms. The percentage of samples positive for SA was high compared with other studies (Foschino et al., 2002; Muehlherr et al., 2003, D'Amico et al., 2008). This can be explained by the fact that the Dutch dairy goat herds are relatively large, with an average of approximately 550 goats. Therefore, the probability that there is an animal present in the flock that sheds $\mathrm{SA}$ is larger than in small flocks. Most values for SPC reported in the literature are in the same range as what we reported (Foschino et al., 2002; Muehlherr et al., 2003; Zeng et al., 2007), but D'Amico et al. (2008) reported lower values. This may be explained by the fact that the latter cultured only raw milk used for farmstead cheese production, which should be of high bacteriological quality. The average $\mathrm{CC}$ in the present investigation was relatively low compared with other studies (Foschino et al., 2002; Zeng et al., 2007; D'Amico et al., 2008). The CC, however, had a high standard deviation and differences between farms were considerable. The $\mathrm{CC}$ is related to hygiene during production, but can also increase as a result of insufficient cooling and refrigeration (Foschino et al., 2002; Zeng et al., 2007). In all the above-mentioned studies, the CC was only a small fraction of SPC. In our study, the 
Table 1. Descriptive statistics of herd-mean $\log _{10}$ SCC, $\log _{10}$ total bacterial count (TBC), $\log _{10} \mathrm{SPC}, \log _{10}$ coliform count (CC), and $\log _{10}$ staphylococcal count (SC) of 3 consecutive bulk milk samples from 53 Dutch dairy goat farms

\begin{tabular}{lccccc}
\hline Variable & Samples, $\mathrm{n}$ & Minimum & Maximum & Mean & SD \\
\hline SCC & 144 & 5.92 & 6.53 & 6.17 & 0.13 \\
TBC & 159 & 4.06 & 4.98 & 4.53 & 0.19 \\
SPC & 159 & 3.85 & 5.56 & 4.55 & 0.43 \\
CC & 159 & 0.00 & 3.82 & 1.61 & 0.92 \\
SC & 159 & 3.19 & 4.69 & 3.88 & 0.35 \\
\hline
\end{tabular}

CC was $1 \%$ of the TBC or $1 \%$ of the SPC, whereas the SC comprised $30 \%$ of the TBC and $31 \%$ of the SPC. This observation indicates that staphylococci are an important group affecting the $\mathrm{TBC}$ or SPC, whereas coliforms contribute only to a limited extent to the total number of bacteria. This is underlined by Table 2 , which shows strong correlations between SC and TBC and $\mathrm{SPC}$, but $\mathrm{CC}$ was only moderately correlated with TBC and not correlated with SPC.

Table 2 shows that TBC was correlated to SPC ( $\mathrm{r}=$ 0.61). In a previous study (Holm et al., 2004) of cows' milk, a higher correlation was reported $(\mathrm{r}=0.71)$. The difference can be explained by the fact that TBC samples were not taken from the same bulk tank as the SPC samples. Surprisingly, TBC was in the same range as SPC (4.53 vs. 4.55). Holm et al. (2004), however, reported much higher values for the TBC method than for the SPC method. This is a result from the fact that the BactoScan counts individual bacterial cells whereas the plate count method counts lumps of bacteria as a single colony forming unit. Furthermore, the BactoScan also counts viable but not culturable bacteria as well as dead cells. The relatively high SPC measurements in our study may be explained by the fact that these samples were stored at a higher temperature than the samples for routine milk quality analysis, which were stored at 2 to $3^{\circ} \mathrm{C}$. The higher temperature may have caused a higher bacterial growth rate. Somatic cell count was correlated to TBC $(\mathrm{r}=0.35)$, which corresponds to findings in an earlier study on a different sample of the same population (Koop et al., 2009).

Table 2. Spearman's rank correlation coefficient between herd-mean $\log _{10}$ SCC, $\log _{10}$ total bacterial count (TBC) ${ }^{1} \log _{10}$ SPC, $\log _{10}$ coliform count (CC), and $\log _{10}$ staphylococcal count (SC) in bulk milk samples from 53 Dutch dairy goat farms

\begin{tabular}{lclll}
\hline Item & TBC & SPC & CC & SC \\
\hline SCC & $0.35^{* *}$ & 0.12 & 0.12 & $0.40^{* *}$ \\
TBC & & $0.61^{* * *}$ & $0.33^{*}$ & $0.51^{* * *}$ \\
SPC & & & 0.19 & $0.53^{* * *}$ \\
CC & & & & -0.03 \\
\hline
\end{tabular}

${ }^{1}$ Sampling moment different from other measurements.

${ }^{*} P<0.05 ;{ }^{* *} P<0.01 ;{ }^{* * *} P<0.001$.
The mixed linear model for the effect of different bacterial groups on SCC is presented in Table 3. The residuals of the model were not sufficiently normally distributed and this problem could not be completely solved in the modeling process. Therefore, the standard errors may have a small downward bias, so the size of the confidence intervals may be underestimated. Nevertheless, the model can be used to assess the relative effect of the variables within the model (Maas and Hox, 2004). The model shows that moment of sampling was an important factor, and SCC decreased from the first to the third sample. Previously, we described that bulk milk SCC in goats has a constant yearly pattern (Koop et al., 2009). It is high in December and January and decreases afterward. It is lowest during the summer months and increases again in autumn. The present study was performed from January to March, so the observed decrease in SCC corresponds with these findings. An association between the presence of SA and SCC was not found, unlike in several reports in cattle (Jayarao et al., 2004; Olde Riekerink et al., 2006; Rysanek et al., 2009). The coliform count was not related to SCC, but the staphylococcal count was. An increase of one $\log _{10}$ step in SC results roughly in an increase of SCC of $10^{5}$ cells $/ \mathrm{mL}$. In goats, staphylococci are the predominant mammary pathogens and are often the cause of subclinical infections (Bergonier et al., 2003; Contreras et al., 2007). Udder infections with SA can strongly increase SCC in goat milk, but because of the relatively low prevalence of infection with this pathogen, little effect on bulk milk level can be expected (Deinhofer and Pernthaner, 1995; Luengo et al., 2004; Moroni et al., 2005). Coagulase-negative staphylococci are known to be opportunistic pathogens that are part of the resident bacteria on teat skin (Jayarao et al., 2004). The presence of staphylococci in bulk milk is therefore not necessarily an indication of intramammary

Table 3. Coefficients $(\beta)$ and CI around $\beta$ of the multivariable linear mixed regression model for $\log _{10}$ SCC, with moment of sampling, coliform count (CC), staphylococcal count (SC), and Staphylococcus aureus detection (SA) as fixed effects and a repeated effect for farm, based on 159 bulk milk samples from 53 Dutch dairy goat farms

\begin{tabular}{lcc}
\hline Item & $\beta$ & $95 \%$ CI $(\beta)$ \\
\hline Intercept & 6.065 & 5.964 to 6.166 \\
Sampling moment & $\operatorname{Ref}^{1}$ & \\
First & -0.039 & -0.065 to -0.014 \\
Second & -0.093 & -0.131 to -0.055 \\
Third & 0.010 & -0.003 to 0.023 \\
CC & 0.035 & 0.011 to 0.059 \\
SC & Ref & \\
SA & 0.000 & -0.024 to 0.024 \\
Absent & & \\
Present &
\end{tabular}

${ }^{1}$ Ref $=$ reference category. 
Table 4. Intraclass correlation coefficient (ICC) and $95 \%$ CI of $\log _{10}$ SCC, $\log _{10}$ total bacterial count (TBC), $\log _{10}$ SPC, $\log _{10}$ coliform count (CC), and $\log _{10}$ staphylococcal count (SC), and prevalence-adjusted, biasadjusted kappa statistic (PABAK) for presence of Staphylococcus aureus (SA) in 3 repeated bulk milk samplings 2 wk apart on 53 Dutch dairy goat farms

\begin{tabular}{lccc}
\hline Variable & 1st vs. 2nd sample & 2nd vs. 3rd sample & 1st vs. 3rd sample \\
\hline ICC, \% (95\% CI) & $83(70$ to 91$)$ & $72(55$ to 83$)$ & 33 (1 to 58$)$ \\
SCC & $27(0$ to 50$)$ & $34(8$ to 56$)$ & 29 (2 52$)$ \\
TBC & $34(8$ to 56$)$ & $22(-5$ to 46$)$ & 36 (10 to 57$)$ \\
SPC & $55(33$ to 71$)$ & $31(5$ to 53$)$ & 51 (28 to 68$)$ \\
CC & $6(-21$ to 32$)$ & $32(6$ to 54$)$ & $45(21$ to 64$)$ \\
SC & $0(-26$ to 24$)$ & $36(11$ to 61$)$ & $9(-17$ to 36$)$ \\
PABAK, \% (95\% CI) & & & \\
SA &
\end{tabular}

infections in the herd. Staphylococcal count, however, showed correlation to SCC in this study. This finding indicates that the number of staphylococci reflects to some extent the udder health status of a herd. Furthermore, staphylococci made an important contribution to the SPC. Therefore, in case of problems with high bacterial counts in the bulk milk, the udder health status of a herd may be one of the factors to investigate.

The level of agreement between the repeated bulk milk measurements is shown in Table 4. The agreement between consecutive SCC measurements is also reported, but these values are biased by the systematic decrease in SCC over time. This probably contributed to the low ICC between the first and third samples. The repeatability of bacterial counts and isolation of SA was low. Surprising are the large differences in agreement between the first and the second, and the second and the third, sampling for SC and SA. This lack of repeatability can be explained in 2 ways. First, it may indicate that bacterial counts, and especially staphylococcal counts, in bulk milk are not very constant over time. Second, it may be an indication of poor repeatability of the test. The flow cytometric bacterial count, used for the TBC estimation, is a highly repeatable technique. The correlation coefficient between the first and the second bacterial count in duplicate samples was 0.99 (Holm et al., 2004). The fact that the TBC also has a low ICC indicates that the repeatability of the test is not the only cause of the poor agreement between consecutive samples. Transportation conditions of the samples may affect the bacterial counts but, more importantly, the bacterial populations in the bulk tank are probably not constant. Therefore, to be able to draw conclusions from bulk milk culturing, repeated samples are necessary.

Differential culturing of goat bulk milk showed that staphylococci comprised about $30 \%$ of the TBC, whereas coliforms made up only about $1 \%$. The number of staphylococci in the bulk milk was related to bulk milk SCC, but presence of SA was not. Repeatability of bulk milk bacterial counts is relatively low. Therefore, repeated samples should be cultured to be able to draw valid conclusions.

\section{ACKNOWLEDGMENTS}

J. van Wegen of the Dutch Association for Quality Assurance in Goat Farming (VKGN) is gratefully acknowledged for organization of the sampling. We thank A. Eggenkamp (Division of Veterinary Public Health, Utrecht University) for her skilled laboratory assistance.

\section{REFERENCES}

Bergonier, D., R. de Cremoux, R. Rupp, G. Lagriffoul, and X. Berthelot. 2003. Mastitis of dairy small ruminants. Vet. Res. 34:689-716.

Contreras, A., R. E. Miranda, A. Sanchez, C. De la Fe, D. Sierra, C. Luengo, and J. C. Corrales. 2008. Presence of Mycoplasma species and somatic cell counts in bulk-tank goat milk. Small Rumin. Res. 75:247-251.

Contreras, A., D. Sierra, A. Sanchez, J. C. Corrales, J. C. Marco, M. J. Paape, and C. Gonzalo. 2007. Mastitis in small ruminants. Small Rumin. Res. 68:145-153.

Corrales, J. C., A. Sanchez, C. Luengo, J. B. Poveda, and A. Contreras, 2004. Effect of clinical contagious agalactia on the bulk tank milk somatic cell count in Murciano-Granadina goat herds. J. Dairy Sci. 87:3165-3171.

D'Amico, D. J., E. Groves, and C. W. Donnelly. 2008. Low incidence of foodborne pathogens of concern in raw milk utilized for farmstead cheese production. J. Food Prot. 71:1580-1589.

de la Fe, C., A. Sánchez, A. Gutierrez, A. Contreras, J. C. Corrales, P. Assunçao, C. Poveda, and J. B. Poveda. 2009. Effects on goat milk quality of the presence of Mycoplasma spp. in herds without symptoms of contagious agalactia. J. Dairy Res. 76:20-23.

Deinhofer, M., and A. Pernthaner. 1995. Staphylococcus spp. as mastitisrelated pathogens in goat milk. Vet. Microbiol. 43:161-166.

Foschino, R., A. Invernizzi, R. Barucco, and K. Stradiotto. 2002. Microbial composition, including the incidence of pathogens, of goat milk from the Bergamo region of Italy during a lactation year. J. Dairy Res. 69:213-225.

Holm, C., T. Mathiasen, and L. Jespersen. 2004. A flow cytometric technique for quantification and differentiation of bacteria in bulk tank milk. J. Appl. Microbiol. 97:935-941.

Jayarao, B. M., S. R. Pillai, A. A. Sawant, D. R. Wolfgang, and N. V. Hegde. 2004. Guidelines for monitoring bulk tank milk somatic cell and bacterial counts. J. Dairy Sci. 87:3561-3573.

Jørgensen, H. J., T. Mørk, H. R. Høgåsen, and L. M. Rørvik. 2005. Enterotoxigenic Staphylococcus aureus in bulk milk in Norway. J. Appl. Microbiol. 99:158-166. 
Koop, G., M. Nielen, and T. van Werven. 2009. Bulk milk somatic cell counts are related to bulk milk total bacterial counts and several herd-level risk factors in dairy goats. J. Dairy Sci. 92:4355-4364.

Kyozaire, J. K., C. M. Veary, I. M. Petzer, and E. F. Donkin. 2005. Microbiological quality of goat's milk obtained under different production systems. J. S. Afr. Vet. Assoc. 76:69-73.

Luengo, C., A. Sanchez, J. C. Corrales, C. Fernández, and A. Contreras. 2004. Influence of intramammary infection and noninfection factors on somatic cell counts in dairy goats. J. Dairy Res. 71:169-174.

Maas, C. J. M., and J. J. J. J. Hox. 2004. The influence of violations of assumptions on multilevel parameter estimates and their standard errors. Comput. Stat. Data Anal. 46:427-440.

Moroni, P., G. Pisoni, G. Ruffo, and P. Boettcher. 2005. Risk factors for intramammary infections and relationship with somatic-cell counts in Italian dairy goats. Prev. Vet. Med. 69:163-173.

Muehlherr, J. E., C. Zweifel, S. Corti, J. E. Blanco, and R. Stephan. 2003. Microbiological quality of raw goat's and ewe's bulk-tank milk in Switzerland. J. Dairy Sci. 86:3849-3856.

National Mastitis Council. 1999. Laboratory Handbook on Bovine Mastitis. Revised ed. National Mastitis Council, Verona, WI.
Olde Riekerink, R. G., H. W. Barkema, S. Veenstra, D. E. Poole, R. T. Dingwell, and G. P. Keefe. 2006. Prevalence of contagious mastitis pathogens in bulk tank milk in Prince Edward Island. Can. Vet. J. $47: 567-572$.

Petrie, A., and P. Watson. 2006. Measuring agreement. Pages 196-201 in Statistics for Veterinary and Animal Science. 2nd ed. Blackwell Publishing, Oxford, UK

Rysanek, D., M. Zouharova, and V. Babak. 2009. Monitoring major mastitis pathogens at the population level based on examination of bulk tank milk samples. J. Dairy Res. 76:117-123.

Scherrer, D. S. Corti, J. E. Muehlherr, C. Zweifel, and R. Stephan. 2004. Phenotypic and genotypic characteristics of Staphylococcus aureus isolates from raw bulk-tank milk samples of goats and sheep. Vet. Microbiol. 101:101-107.

Tirard-Collet, P., J. A. Zee, L. Carmichael, and R. E. Simard. 1991 A study of the microbiological quality of goat milk in Quebec. J. Food Prot. 54:263-266.

Zeng, S. S., S. S. Chen, B. Bah, and K. Tesfai. 2007. Effect of extended storage on microbiological quality, somatic cell count, and composition of raw goat milk on a farm. J. Food Prot. 70:12811285 . 